\title{
Effects of Sulfur Content and Sulfide-forming Elements Addition on Impact Properties of Ferrite-Pearlitic Microalloyed Steels
}

\author{
N. TSUNEKAGE and H. TSUBAKINO'1)
}

Technological Research Laboratory, Sanyo Special Steel Co., Ltd., Nakashima, Shikama-ku, Himeji, Hyogo $672-8677$ Japan.

1) Faculty of Engineering, Himeji Institute of Technology, Shosha, Himeji, Hyogo 671-2201 Japan.

(Received on December 6, 2000; accepted in final form on January 31, 2001)

\begin{abstract}
Longitudinal Charpy impact value of ferrite-pearlitic microalloyed steel was improved by large addition of S (0.05-0.1mass\%), however, transverse Charpy impact value was rather deteriorated. This study focused on the sulfide shape, which have large effects on impact properties. The elements of $\mathrm{Ca}, \mathrm{Mg}, \mathrm{Ti}, \mathrm{and} \mathrm{Zr}$ were added to ferrite-pearlitic microalloyed steels with 0.1 mass $\% \mathrm{~S}$ for sulfide shape control, and their impact properties were compared. The addition of $\mathrm{Ca}$ or $\mathrm{Mg}$ to the steels improved the transverse Charpy impact value without changing the longitudinal Charpy impact value, while the addition of $\mathrm{Ti}$ or $\mathrm{Zr}$ to the steels resulted in deteriorating significantly both longitudinal and transverse Charpy impact values. The crack initiation energy of the $\mathrm{Ca}$ or $\mathrm{Mg}$ bearing steels improves by enlargement of the minute dimple area ratio in the ductile fracture surface because the elongation of sulfides in the hot forging process are controlled by the addition of $\mathrm{Ca}$ or $\mathrm{Mg}$. On the other hand, the reason why the Charpy impact value of $\mathrm{Ti}$ or $\mathrm{Zr}$ bearing steels are deteriorated is that $(\mathrm{Ti}, \mathrm{V}) \mathrm{C}$ or plate type sulfides promote cleavage fracture and then raise their ductileto-brittle transition temperature.
\end{abstract}

KEY WORDS: sulfide; shape control; microalloyed steel; toughness; Charpy impact test; fracture surface.

\section{Introduction}

Ferrite-pearlitic microalloyed steels for hot forging, which show enough strength by air cooling from hot forging temperature, are widely used as substitutes of quenched and tempered martensitic steels because of cost reduction merits by the omission of quenching and tempering processes. However, the toughness of ferrite-pearlitic microalloyed steels is inferior to quenched and tempered martensitic steels, and the toughness improvement is desirable for the extension of their applications.

Microstructure refining is one way to improve the toughness without sacrificing the strength of the steels. Particularly, microstructure control by precipitate is very effective because it can be applied in current manufacturing process. Microstructure control by sulfides has been considered to improve the toughness of microalloyed steels, ${ }^{1-4)}$ heat-affected zone of weld metals, ${ }^{5)}$ silicon steel sheets, ${ }^{6}$ ) etc. because sulfides can retard austenite grain growth since sulfides are relatively stable among the precipitates at hot forging temperatures, and sulfides promote the formation of intragranular ferrite.

However, sulfides cause the deterioration of transverse impact properties because they become relatively large inclusions and elongate to the hot rolling or forging direction. There are two methods which are considered to improve the impact property anisotropy; (A) minute sulfides dispersion by the control of precipitates which work as nucleation sites of sulfides, and (B) sulfide shape control by the addition of sulfide-forming elements. As for (A), the representative nucleation sites of sulfides are oxides, and investigations of the increase of the number of oxides and modification of oxides compositions so that sulfides easily nucleate have been in progress. ${ }^{7,8)}$ However, the control of oxides dispersion need to solve some technical issues such as the shortening of the deoxidation time, the increase of solidification speed, and so on.

As for (B), a lot of studies have been carried out; for instance, $\mathrm{Ca},{ }^{9-14)} \mathrm{Mg},{ }^{12,13)} \mathrm{Ti}^{15-17)} \mathrm{Zr},{ }^{15,16)} \mathrm{REM},{ }^{15-18)}$ were applied to improve the anisotropy by the sulfides shape control. Most of these studies were intended to control sulfides which exist as impurities. Studies on the effect of intentional $\mathrm{S}$ addition and comparison of the effects of sulfide-forming elements addition to steels such as microstructure controlled steels or free-cutting steels are too few.

The purpose of this study is to improve the impact properties of ferrite-pearlitic microalloyed steels by sulfides control. At first, the effects of S content on impact properties was clarified, then the possibility to improve transverse impact properties by the control of sulfides morphology and dispersion with the addition of representative sulfide-forming elements such as $\mathrm{Ca}, \mathrm{Mg}$, $\mathrm{Ti}$, and $\mathrm{Zr}$ was investigated.

\section{Experimental Procedures}

\subsection{Effects of S Content}

The chemical compositions of materials for the investigation of the effects of S content on toughness of ferrite- 
Table 1. Chemical compositions of steels investigated. (mass\%)

\begin{tabular}{cccccccccc}
\hline Steels & $\mathrm{C}$ & $\mathrm{Si}$ & $\mathrm{Mn}$ & $\mathrm{S}$ & $\mathrm{V}$ & $\mathrm{s}-\mathrm{Al}$ & $\mathrm{N}$ & $\mathrm{Cu}$ & $\mathrm{Ca}, \mathrm{Mg}, \mathrm{Ti}, \mathrm{Zr}$ \\
\hline $\mathrm{A}$ & 0.45 & 0.25 & 0.77 & 0.001 & 0.12 & 0.026 & 0.0092 & 0.10 & - \\
$\mathrm{B}$ & 0.43 & 0.26 & 0.92 & 0.010 & 0.11 & 0.026 & 0.0088 & 0.10 & - \\
$\mathrm{C}$ & 0.46 & 0.24 & 0.88 & 0.050 & 0.10 & 0.021 & 0.0064 & 0.12 & - \\
$\mathrm{D}$ & 0.46 & 0.24 & 0.94 & 0.114 & 0.10 & 0.018 & 0.0060 & 0.10 & - \\
$\mathrm{E}$ & 0.45 & 0.25 & 1.20 & 0.176 & 0.09 & 0.022 & 0.0062 & 0.11 & - \\
\hline Dca & 0.47 & 0.23 & 0.93 & 0.096 & 0.10 & 0.027 & 0.0050 & 0.12 & $0.0057(\mathrm{Ca})$ \\
Dmg & 0.44 & 0.22 & 0.91 & 0.098 & 0.08 & 0.019 & 0.0057 & 0.11 & $0.0032(\mathrm{Mg})$ \\
Dti & 0.43 & 0.25 & 0.77 & 0.104 & 0.11 & 0.024 & 0.0038 & 0.12 & $0.25(\mathrm{Ti})$ \\
Dzr & 0.44 & 0.26 & 0.77 & 0.104 & 0.10 & 0.029 & 0.0035 & 0.12 & $0.24(\mathrm{Zr})$ \\
\hline
\end{tabular}

pearlitic microalloyed steels are shown in Table 1, as steels A, B, C, D, and E. These steels have different S content, from 0.001 to $0.176 \operatorname{mass} \%$. Manganese is added to these steels in the amount equivalent to atomic $\%$ of $\mathrm{S}$ content to compensate the increase of the amount of $\mathrm{MnS}$ inclusions formation. A $100 \mathrm{~kg}$ ingots of these five steels were made with a vacuum melting furnace. They were forged into $40 \times 65 \mathrm{~mm}$ square bars at $1200^{\circ} \mathrm{C}$ (forging ratio: ca. 10) and were reheated at $1200^{\circ} \mathrm{C}$ for $3.6 \mathrm{ks}$ and air-cooled to room temperature in order to homogenize the microstructure and hardness. Longitudinal and transverse Charpy impact specimens (ISO/DIS 148-1, 2 mm U-notch) were machined from the forged bars. Charpy impact tests were carried out at $20^{\circ} \mathrm{C}$.

\subsection{Effects of Sulfide-forming Elements Addition}

Sulfide-forming elements to be examined in this study are required to have a higher sulfide-forming tendency than $\mathrm{Mn}$ to control the sulfide shape, because the structural steels contain a certain amount of $\mathrm{Mn}$. The order of tendency at around $1500^{\circ} \mathrm{C}$ by the standard free energy of sulfide formation is as follows: $\mathrm{Ca}>\mathrm{Sr} \fallingdotseq \mathrm{Ba} \fallingdotseq \mathrm{La} \fallingdotseq \mathrm{Ce}>\mathrm{Nd}>\mathrm{Th}>$ $\mathrm{U}>\mathrm{Mg}>\mathrm{Zr}>\mathrm{Ti}>\mathrm{Mn}>\mathrm{F}$. Kaneko et al. ${ }^{19)}$ studied the sulfide-forming tendency in steels and determined the order of tendency to be as follows: $\mathrm{Zr}>\mathrm{Ti}>\mathrm{Mn}>\mathrm{Nb}>\mathrm{V}>\mathrm{Cr}>\mathrm{Al}>$ $\mathrm{Mo}>\mathrm{W}>\mathrm{Fe}$. Further, Kaneko et al. ${ }^{19)}$ predicted that the sulfide-forming tendency of $\mathrm{Ca}, \mathrm{Mg}, \mathrm{Ce}, \mathrm{Ba}, \mathrm{Sr}$ etc. were strong enough although they were not shown in the above order because it was difficult for them to retain in steels. Therefore, $\mathrm{Ca}, \mathrm{Mg}, \mathrm{Ti}$, and $\mathrm{Zr}$ were examined as sulfideforming elements in this study in consideration of environmental burden property and costs.

The chemical compositions of materials for the investigation of the effects of sulfide-forming elements addition are shown in Table 1, as steels Dca, Dmg, Dti, and Dzr. While their basic chemical compositions are the same as steel $\mathrm{D}$, they contain $\mathrm{Ca}, \mathrm{Mg}, \mathrm{Ti}$, and $\mathrm{Zr}$, respectively. A $100 \mathrm{~kg}$ ingots of these four steels were made with a vacuum melting furnace. The elements of $\mathrm{Ca}, \mathrm{Mg}$, $\mathrm{Ti}$, and $\mathrm{Zr}$ were added into molten steels after $\mathrm{Al}$ deoxidation just before casting because they were expected to act as deoxidation elements. Furthermore, Mn content in the steels Dca and Dmg increased because the sulfides compositions of these steels were expected to be mainly derived from $\mathrm{MnS}$ inclusions. These ingots were forged and reheated by the same procedure described in the previous section, then they were subjected to the Charpy impact test at $20^{\circ} \mathrm{C}$. Different reheating temperatures from $1100^{\circ} \mathrm{C}$ to $1300^{\circ} \mathrm{C}$ were adopted.

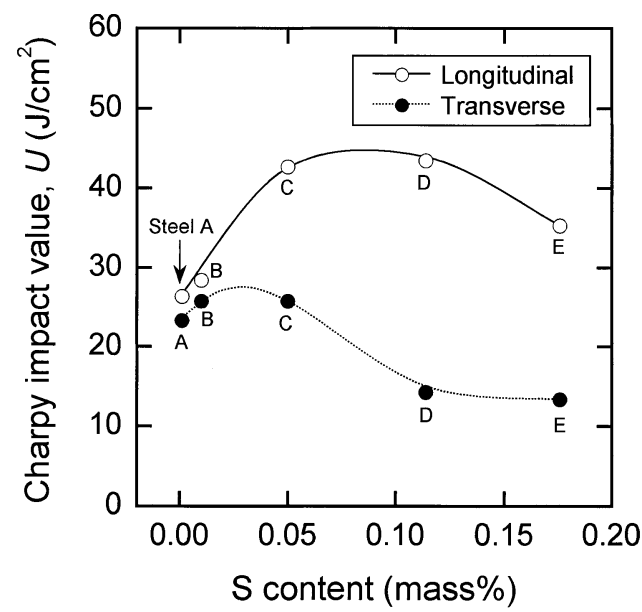

Fig. 1. Influence of sulfur content on Charpy impact value tested at $20^{\circ} \mathrm{C}$.

Prior austenite grain size, hardness by Rockwell C scale, and inclusion parameters were examined for the Charpy impact specimens for the sake of discussion of the results of the Charpy impact test. The specimens for measurement of prior austenite grain size were etched by saturated picric acid solution with surface active agents before optical microscope observation. Ingots and forged bars were used as specimens to measure the inclusion parameters. The specimens from the ingots were etched by selective potentiostatic etching by electrolytic dissolution method with 5 mass $\%$ tetramethylammonium chloride-10 vol\% acetylacetonemethanol solution, then they were observed by scanning electron microscope (SEM) with energy dispersive X-ray spectrometer (EDX). The inclusions in the forged bars were also observed by SEM-EDX. The inclusions parameters such as the number $N$, length $L$, aspect ratio $\lambda$ (the ratio of length to width of inclusions) and area ratio $f$ were measured at magnification of 400 by computer aided image analysis of the specimens, with an inspected area of 1.04 $\mathrm{mm}^{2}$. The minimum size of inclusions which can be measured by this method was $0.5 \mu \mathrm{m}$ in maximum length. The precipitates extracted from the specimens, which were air cooled from $1200^{\circ} \mathrm{C}$, were analyzed by $200 \mathrm{kV}$ transmission electron microscope (TEM). Furthermore, X-ray diffraction method was used for inclusions identification.

\section{Experimental Results}

\subsection{Charpy Impact Properties}

\subsubsection{Effects of S Content}

Figure 1 shows the relationship between $\mathrm{S}$ content and Charpy impact value $U$ at $20^{\circ} \mathrm{C}$. The highest longitudinal impact value is obtained at $0.05-0.1$ mass $\% \mathrm{~S}$ content. However, the transverse Charpy impact value decreases when the $\mathrm{S}$ content is increased up to $0.1 \mathrm{mass} \%$. The prior austenite grain size number is 0.9 at $0.001 \mathrm{mass} \% \mathrm{~S}$, while the number is 4.1 at 0.114 mass $\% \mathrm{~S}$ reheating at $1200^{\circ} \mathrm{C}$. Further, the ratio of $\mathrm{MnS}$ inclusions as nucleation site of intragranular ferrite is $94.4 \%$. Therefore, the reason why the impact value is improved by the increase of $\mathrm{S}$ content may be related to the suppression effect of austenite grain growth in the austenitizing process and the promotion effect of intragranular ferrite by $\mathrm{MnS}$ inclusions. 


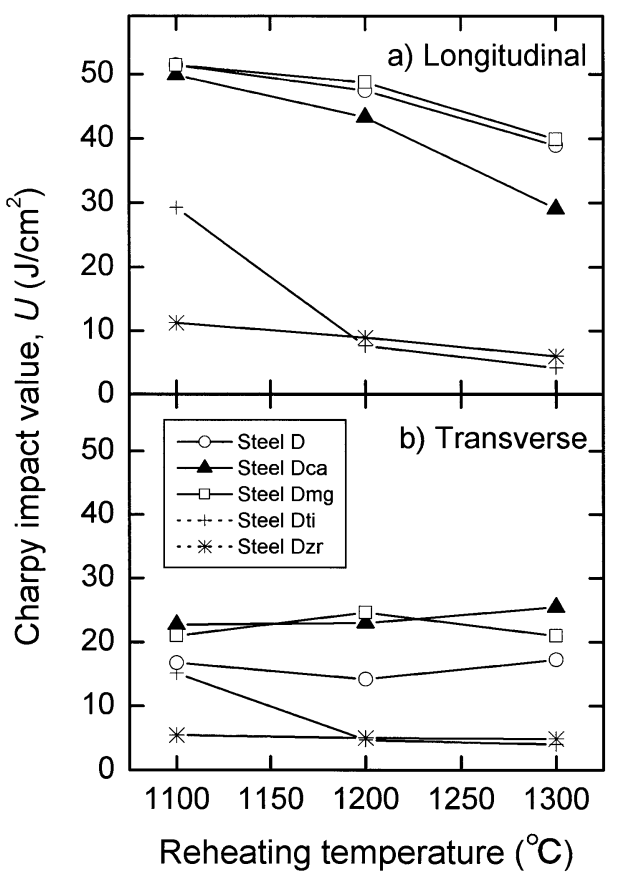

Fig. 2. Influence of reheating temperature on Charpy impact value tested at $20^{\circ} \mathrm{C}$.

As for the longitudinal impact properties, there is a possibility that the impact value is also improved by the stress relief at the ends of cracks and the changing crack propagation direction by the $\mathrm{MnS}$ inclusions because the crack propagation direction is perpendicular to the elongating direction of $\mathrm{MnS}$ inclusions. As for transverse impact properties, the deterioration due to the $\mathrm{MnS}$ inclusions is greater than the improvement effect of the refinement of microstructure by $\mathrm{MnS}$ inclusions because the crack propagation is parallel to the elongating direction of $\mathrm{MnS}$ inclusions. Therefore, the control of the sulfides shape is necessary to improve the transverse Charpy impact properties.

\subsubsection{Effects of Sulfide-forming Elements Addition}

Figures 2(a) and 2(b) show the results of longitudinal and transverse Charpy impact tests at $20^{\circ} \mathrm{C}$. The specimens are steels D, Dca, Dmg, Dti, and Dzr in Table 1. As the reheating temperature increases, the longitudinal impact values of all steels decrease gradually. The steels D and Dmg show almost the same impact value. The tendency of steel Dca is also similar to those of steels D and Dmg, although the impact value of steel Dca is slightly lower than steels D and Dmg. The impact value of steels Dti and Dzr is significantly lower than those of steels D, Dca, and Dmg.

While the transverse Charpy impact value of steels Dca and Dmg is higher than that of steel D in the range of all reheating temperatures, the value for steels Dti and Dzr is lower than that of the steel D. Steel Dti has a characteristic that both transverse and longitudinal Charpy impact values decrease greatly when the reheating temperature increasing from $1100^{\circ} \mathrm{C}$ to $1200^{\circ} \mathrm{C}$.

\subsection{Microstructure and Hardness}

It is well known that there is a correlation between grain size and ductile-to-brittle transition temperature (DBTT) ${ }^{20)}$ Figure 3 shows the relationship between prior austenite grain size $d_{\gamma}^{-1 / 2}$ and DBTT. The correlation between $d_{\gamma}^{-1 / 2}$

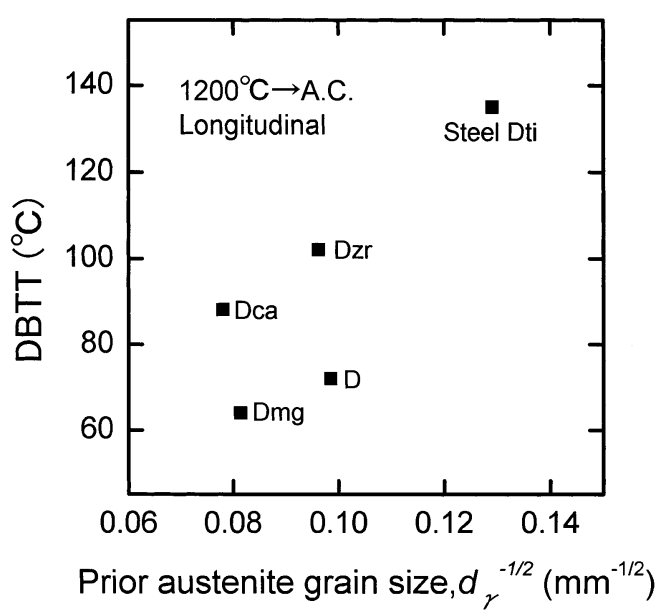

Fig. 3. Influence of prior austenite grain size on ductile-brittle transition temperature (DBTT).

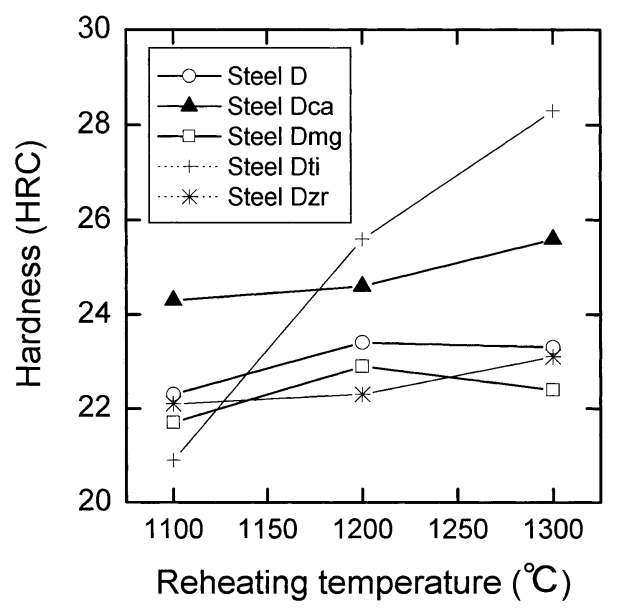

Fig. 4. Influence of reheating temperature on hardness.

and DBTT is not apparent from this figure. It is especially not expected that $d_{\gamma}$ of steel Dti would be the finest of all specimens while its DBTT is highest.

Chiba et $a l .^{21)}$ reported that the impact properties of microalloyed steels deteriorated more as the hardness of the specimens increased. Figure 4 shows the relationship between reheating temperature and hardness. Steel Dti has the property that its hardness increases as the reheating temperature increases, on the other hand, the hardness of other steels changes very little when reheating temperature changes. The hardness of steel Dca is relatively higher than other steels for all reheating temperatures because $\mathrm{C}$ and Mn content in steel Dca are higher than other steels by unevenness of steel making process. Figure $\mathbf{5}$ shows the relationship between the hardness of specimens after cooling from $1200^{\circ} \mathrm{C}$ and the Charpy impact value $U$. The longitudinal Charpy impact value of steels D, Dca, and Dmg may be related to their hardness. As for the transverse Charpy impact value, steels Dca and Dmg are higher than steel D. Neither the longitudinal nor transverse Charpy impact value of steels Dti and Dzr are related to their hardness.

So far, it appears that inclusion morphology affected impact properties greatly, because it is impossible to explain these results by microstructure or hardness. 


\subsection{Inclusions}

Figure 6 shows the SEM micrographs and chemical compositions (atomic $\%$ ) of sulfides in ingots. The basic chemical compositions of sulfides in steel D are MnS. Fe and $\mathrm{Cu}$ are also observed in the MnS. Following the classification of Sims et al., ${ }^{22)}$ the type II which is eutectic $\mathrm{MnS}$ (rod-like type) and the type III which is crystallized $\mathrm{MnS}$ at higher temperature (equiaxed type) are observed. The dif-

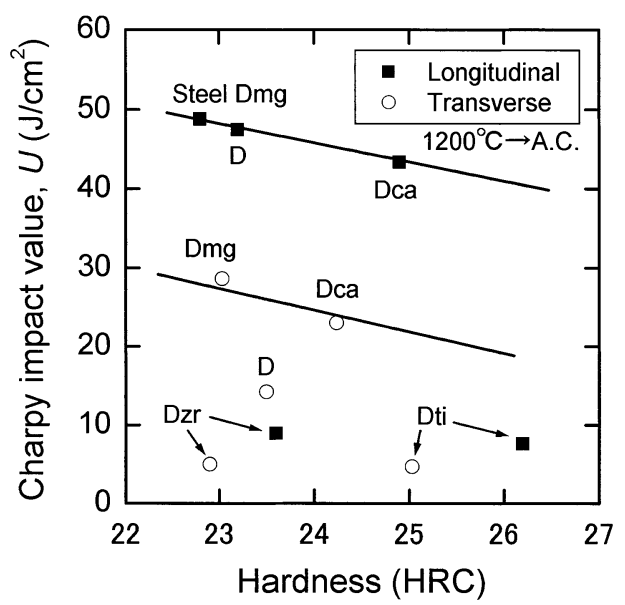

Fig. 5. Influence of hardness on Charpy impact value tested at $20^{\circ} \mathrm{C}$ ference of chemical compositions between type II and type III are not apparent.

The sulfides in steels Dca and Dmg are of the deformed type III, while Type II is not observed. The basic chemical compositions of sulfides in steels Dca and Dmg are the same as that of steel D. Also, $\mathrm{Ca}$ and $\mathrm{Mg}$ were observed respectively in these sulfides. Therefore, the sulfides in steels Dca and Dmg are single phase ( $\mathrm{Mn}, \mathrm{Ca}) \mathrm{S}$ and $(\mathrm{Mn}, \mathrm{Mg}) \mathrm{S}$, respectively.

There are MnS inclusions of the type III and Ti sulfides whose shapes are plate-like or rod-like in steel Dti. As for steel Dzr, there are type III MnS inclusions, large plate-type $\mathrm{Zr}$ sulfides, and $\mathrm{Zr}$ sulfides which are covered with $\mathrm{MnS}$ inclusions. The residues of electrolytic extraction are analyzed by X-ray diffractometer to identify the sulfides in steels Dti and Dzr. The results are shown in Fig. 7. It is verified that $\mathrm{Ti}$ sulfides in steel Dti are $\mathrm{Ti}_{2} \mathrm{CS}$, and that $\mathrm{Zr}$ sulfides in steel Dzr are $\mathrm{Zr}_{2} \mathrm{CS}$. If the all sulfides in these steels change into $\mathrm{Ti}_{2} \mathrm{CS}$ or $\mathrm{Zr}_{2} \mathrm{CS}$, Ti or $\mathrm{Zr}$ content must be 3.0 or 5.7 times to $\mathrm{S}$ content, respectively by the stoichiometric calculation. Therefore, the reason why $\mathrm{MnS}$ inclusions are generated in steels Dti and Dzr may be that $\mathrm{Ti}$ and $\mathrm{Zr}$ content are not sufficient in the steels. As shown in Fig. 6., C amount is not given in the chemical compositions of the sulfides. This is because the EDX can not determine light weight elements such as $\mathrm{C}$, due to its properties.

Figure 8 shows SEM micrographs and the chemical
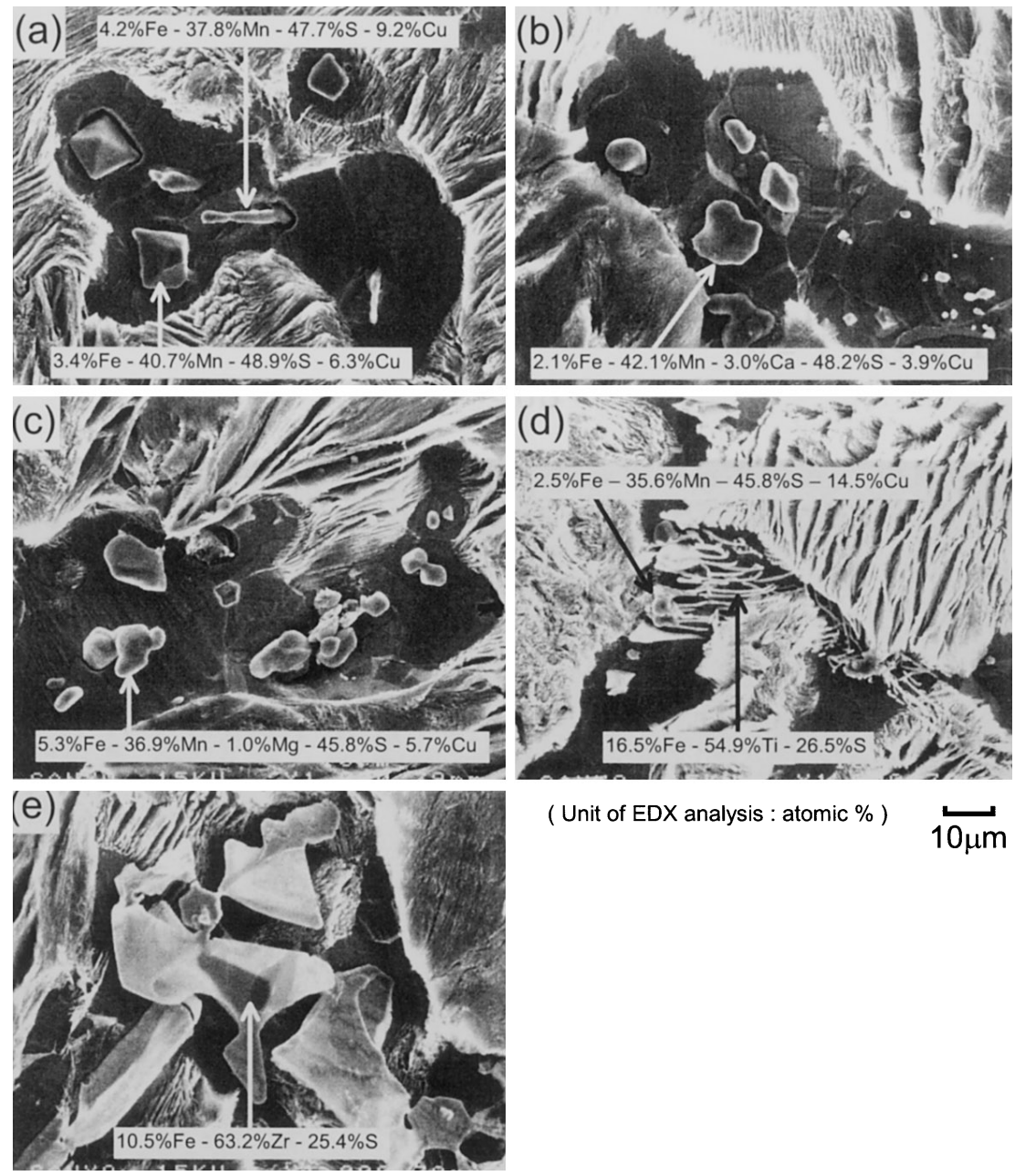

( Unit of EDX analysis : atomic \% ) $10 \mu \mathrm{m}$

Fig. 6. SEM micrographs and chemical compositions of sulfides in ingots: (a) steel D, (b) steel Dca, (c) steel Dmg, (d) steel Dti, and (e) steel Dzr. 
compositions of the representative sulfides in the forged bars. In this case, the Fe content in the sulfides could not be distinguished from that in the matrix, therefore Fig. 8. shows the chemical compositions except Fe. The type and morphology of major sulfides in both as-cast and as-forged specimens are summarized in Table 2. Further, Table 3 shows the measured parameters of inclusions in the forged bars. These results include the parameters of not only sul-

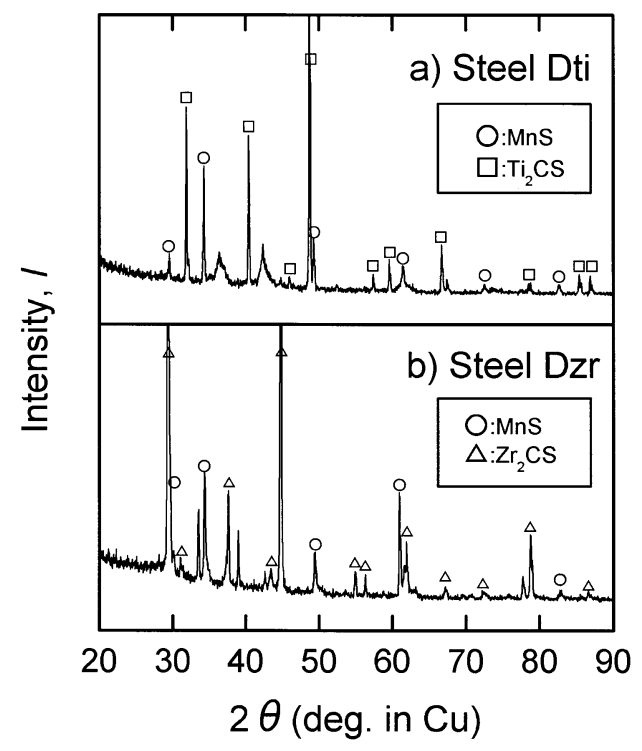

Fig. 7. X-ray diffraction of sulfides in steels Dti and Dzr.
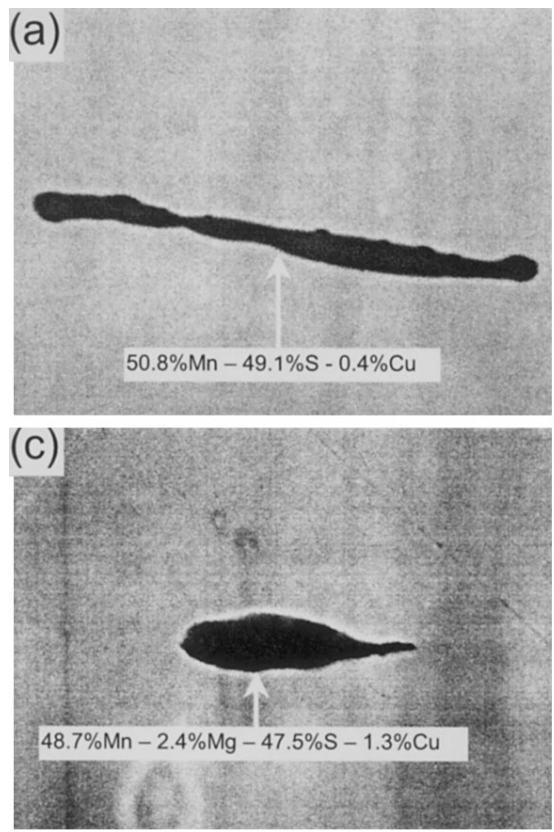

(e)

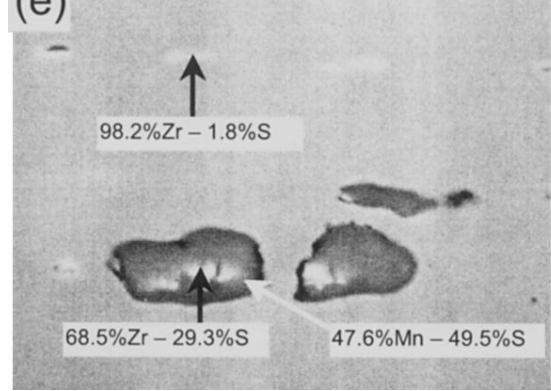

fides, but also of other inclusions, however the parameters show sulfides characteristics because almost all the inclusions are made up by sulfides. The average length $L$ and aspect ratio $\lambda$ of sulfides in steels Dca and Dmg are smaller than those of steel D as shown in Table 3. Therefore, it is obvious that $\mathrm{Ca}$ or $\mathrm{Mg}$ addition makes the sulfides elongate less easily in the hot forging process, even when specimens contain large amounts of $\mathrm{S}$, such as the materials in this study.

Table 2. Type and morphology of major sulfides.

\begin{tabular}{cccc}
\hline Steels & Sulfide type & \multicolumn{2}{c}{ Sulfide morphology } \\
\cline { 3 - 4 } & & As-cast & As-forged \\
\hline $\mathrm{D}$ & $\mathrm{MnS}$ & $\begin{array}{c}\text { Equiaxed and rod-like } \\
\text { (type III and II)* }\end{array}$ & Elongated \\
& & Equiaxed (type III)* & Slightly elongated \\
Dca & $(\mathrm{Mn}, \mathrm{Ca}) \mathrm{S}$ & Equiaxed (type III)* & Slightly elongated \\
Dmg & $(\mathrm{Mn}, \mathrm{Mg}) \mathrm{S}$ & Rod and plate-like & Broken into small pieces \\
Dti & $\mathrm{Ti}_{2} \mathrm{CS}$ & Large plate-like & Broken into small pieces \\
Dzr & $\mathrm{Zr}_{2} \mathrm{CS}$ & Classification of Sims et al. ${ }^{22)}$
\end{tabular}

Table 3. Measured parameters of inclusions. (as-forged)

\begin{tabular}{ccccc}
\hline Steels & Number, $N\left(\mathrm{~mm}^{-2}\right)$ & $\begin{array}{c}\text { Av. length, } \\
L(\mu \mathrm{m})\end{array}$ & $\begin{array}{c}\text { Av. aspect ratio, } \\
(\text { length/width) }\end{array}$ & $\begin{array}{c}\text { Area ratio, } \\
f(\%)\end{array}$ \\
\hline D & 316 & 11.3 & 5.5 & 0.57 \\
Dca & 356 & 6.0 & 3.0 & 0.43 \\
Dmg & 470 & 7.4 & 4.4 & 0.52 \\
Dti & 1774 & 3.7 & 3.0 & 0.85 \\
Dzr & 1093 & 4.0 & 2.6 & 0.82 \\
\hline
\end{tabular}
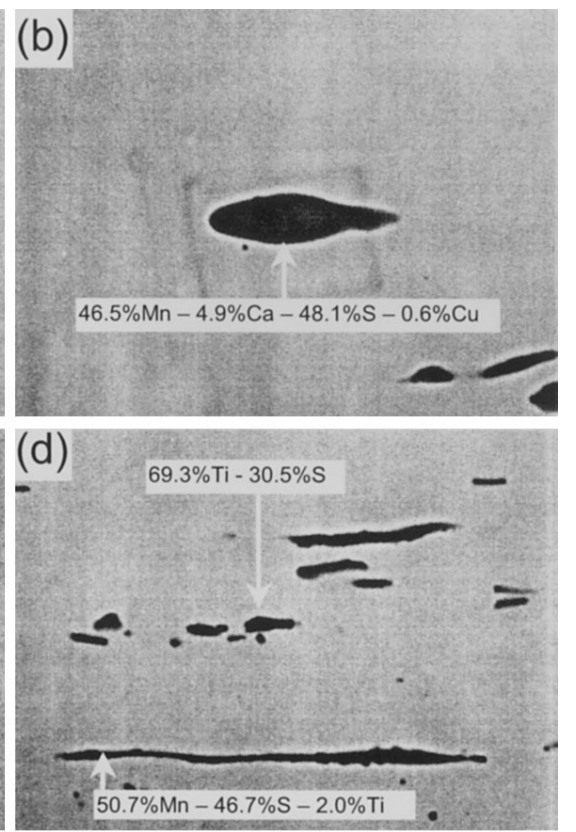

( Unit of EDX analysis : atomic \% )

$10 \mu \mathrm{m}$

Fig. 8. SEM micrographs and chemical compositions of sulfides in bar steels: (a) steel D, (b) steel Dca, (c) steel Dmg, (d) steel Dti, and (e) steel Dzr. 


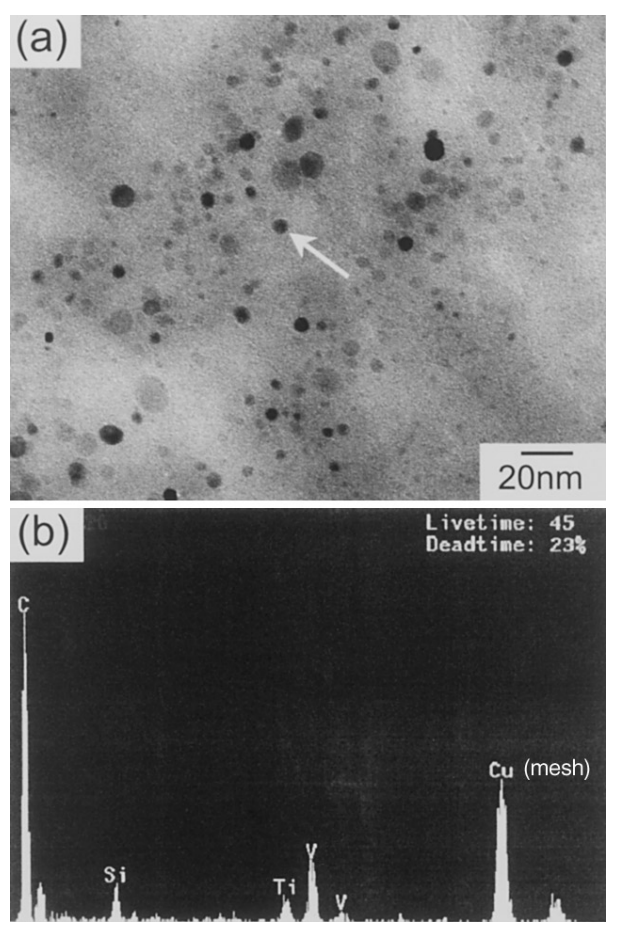

Fig. 9. (a) Bright field TEM micrograph and (b) EDX spectrum of precipitate in steel Dti.

As for steels Dti and Dzr, average length $L$ and aspect ratio $\lambda$ are smaller and the number $N$ and area ratio $f$ are larger. Those inclusions are made up almost by small sulfides. Especially, there is a characteristic that the sulfides number for steels Dti and Dzr is different in each observation field. It can be said that the rod-like or plate-like sulfides in the ingots of steels Dti and Dzr are broken into small pieces by hot forging because $\mathrm{Ti}_{2} \mathrm{CS}$ and $\mathrm{Zr}_{2} \mathrm{CS}$ can not be deformed. ${ }^{15)}$ This means that the mechanisms of sulfides shape control are different between the group of $\mathrm{Ti}$ and $\mathrm{Zr}$ and the group $\mathrm{Ca}$ and $\mathrm{Mg}$. $\mathrm{Cu}$ content in sulfides which consist mainly of $\mathrm{MnS}$ is smaller in all forged bars than in the ingots. This reason is not clear yet, but there is a possibility that $\mathrm{Cu}_{2} \mathrm{~S}$ is concentrated into $\mathrm{MnS}$ in the ingots by solidification segregation because Morrogh ${ }^{23)}$ reported that phase $\mathrm{Cu}_{2} \mathrm{~S}$ may be formed in cast iron, but only if the $\mathrm{Mn}$ content is very low and $\mathrm{Cu}$ and $\mathrm{S}$ contents are high, then $\mathrm{Cu}_{2} \mathrm{~S}$ dissolved into matrix at reheating process before hot forging.

Furthermore, minute inclusions which can not be observed by optical microscope were observed by TEM because there is a possibility that the inclusions can affect impact properties. VC of $c a$. $10 \mathrm{~nm}$ is observed in steels D, Dca, Dmg, and Dzr after cooling from $1200^{\circ} \mathrm{C}$. (Ti, V)C of ca. $10 \mathrm{~nm}$ is observed in steel Dti as shown in Fig. 9. The pinning effect of (Ti, V)C gave the smallest $d_{\gamma}$ for steel Dti. The increasing of hardness of steel Dti at higher reheating temperature is probably caused by the increase of $(\mathrm{Ti}, \mathrm{V}) \mathrm{C}$ with precipitation hardening effect because the solute $\mathrm{Ti}$ content in austenite increases as temperature rises.

The smallest $\mathrm{Ti}_{2} \mathrm{CS}$ and $\mathrm{Zr}_{2} \mathrm{CS}$ inclusions in the forged bars of steels Dti and Dzr are scores nm. Moreover, TiCN and $\beta-\mathrm{Zr}$ inclusions, whose sizes are from hundreds of $\mathrm{nm}$ to several $\mu \mathrm{m}$, are observed. Therefore, the large area ratio $f$ of steels Dti and Dzr in Table 2 is caused by these inclu-

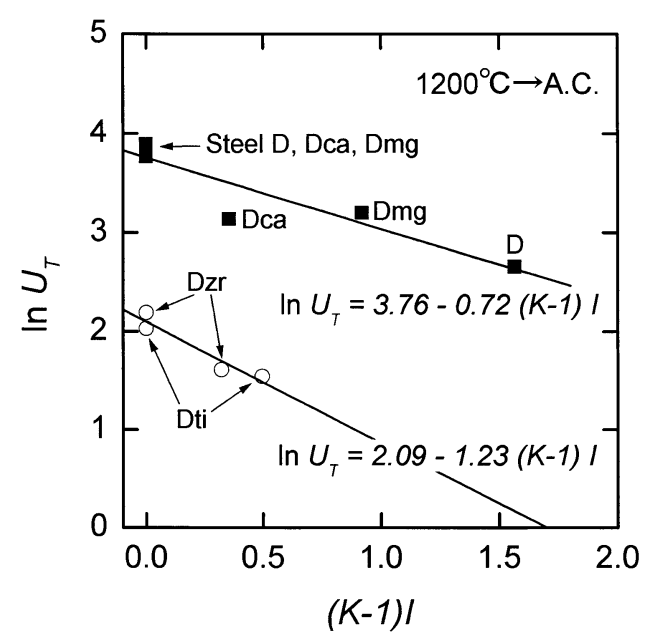

Fig. 10. Relationship between $(K-1) I$ and $\ln U_{\mathrm{T}}$.

sions.

\section{Discussion}

While the sulfides shapes were controlled by the addition of $\mathrm{Ca}, \mathrm{Mg}, \mathrm{Ti}$, and $\mathrm{Zr}$, there was a big difference between the case of $\mathrm{Ca}, \mathrm{Mg}$ addition and the case of $\mathrm{Ti}, \mathrm{Zr}$ addition. The reasons were discussed by the Eq. (1), proposed by Jiang et al. ${ }^{9}$

$$
\ln U_{\mathrm{T}}=\ln U_{\mathrm{L}}-m(K-1) I \ldots
$$

where $U_{\mathrm{T}}$, and $U_{\mathrm{L}}$ mean the transverse and the longitudinal Charpy impact values, respectively, and $m$ is constant. $K$ is the ratio of stress concentration factors of sulfides for the transverse and longitudinal directions, as per Eq. (2). I indicates the total length of sulfides per unit length of steel matrix, as per Eq. (3).

$$
\begin{gathered}
K=(1+2 \lambda) /(1+2 / \lambda) . \\
I=L \cdot N^{1 / 2} \ldots \ldots \ldots \ldots . .
\end{gathered}
$$

Figure 10 shows the relationship between $\ln U_{\mathrm{T}}$ and $(K-1) I$ of this study. Where the intercept $\ln U_{\mathrm{L}}$ is used. $\ln U_{\mathrm{T}}$ of steels D, Dca, and Dmg is describes as follows:

$$
\ln U_{\mathrm{T}}=3.76-0.72(K-1) I \ldots
$$

It is found that the $\ln U_{\mathrm{T}}$ of steels Dca and Dmg improves by controlling the shape of $\mathrm{MnS}$ inclusions.

On the other hand, the $\ln U_{\mathrm{T}}$ of steels Dti and Dzr is described as follows:

$$
\ln U_{\mathrm{T}}=2.09-1.23(K-1) I \ldots
$$

The $\ln U_{\mathrm{T}}$ of Eq. (5) is lower than that of Eq. (4), in case that $(K-1) I$ is the same. The slope $m$ of Eq. (5) is steeper than that of Eq. (4). The fracture surfaces of transverse Charpy specimens were examined to investigate the reason why the tendency changed such as in Eqs. (4) and (5). Figure 11 shows the SEM micrographs of fracture surfaces of specimens after air cooling from $1100^{\circ} \mathrm{C}$. The fracture surfaces of steels D, Dca, and Dmg are similar, ductile around the notches, while the other parts are brittle. However, ductile fracture surface areas around the notches become smaller if the reheating temperature is raised. 

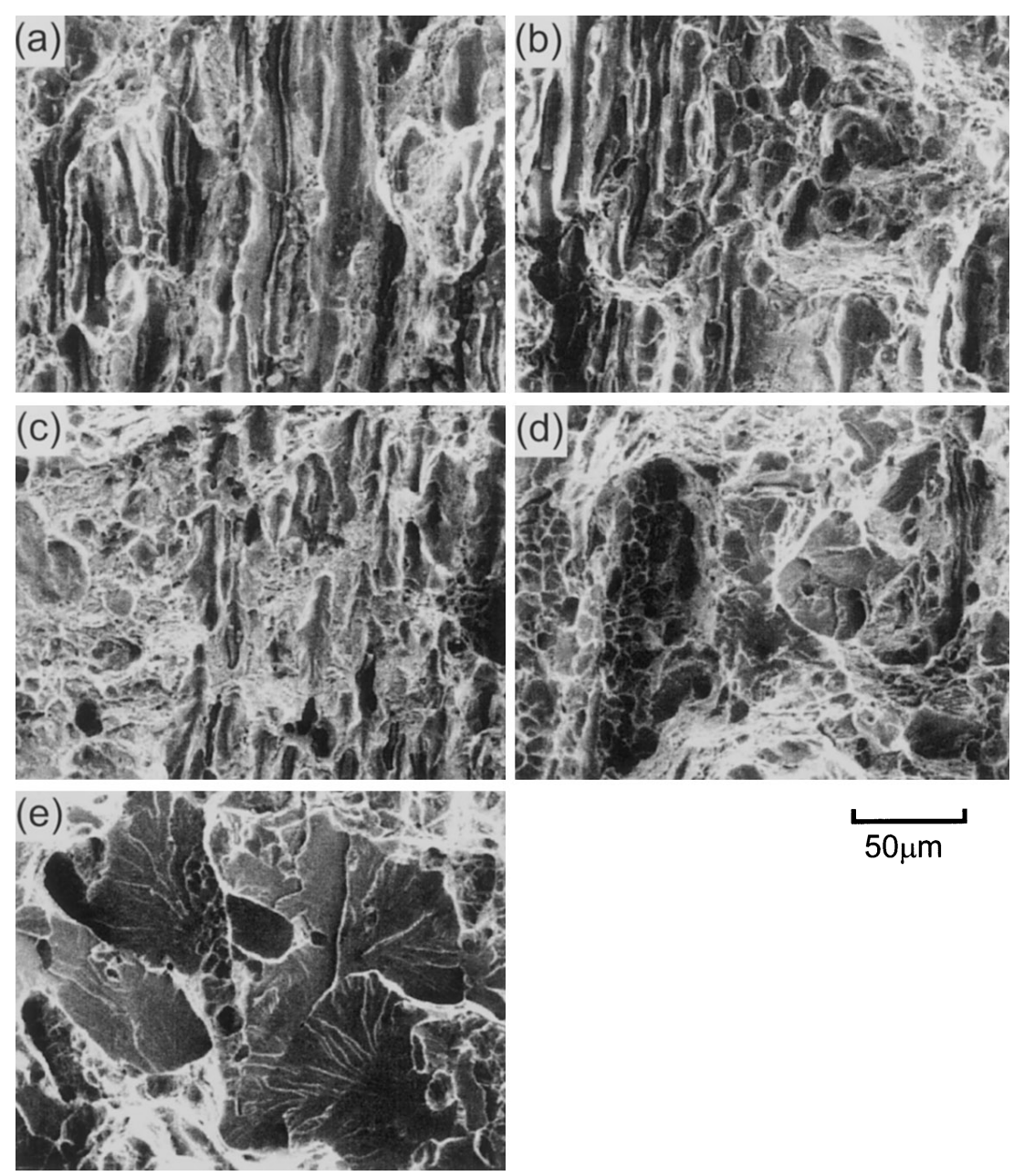

Fig. 11. SEM micrographs of fracture surfaces around the notches of transverse Charpy specimens after air cooling from $1100^{\circ} \mathrm{C}$ : (a) steel D, (b) steel Dca, (c) steel Dmg, (d) steel Dti, and (e) steel Dzr.

Although the fracture surface of steel Dti after air cooling from $1100^{\circ} \mathrm{C}$ is similar to that of steels D, Dca, and Dmg, the fracture surfaces of steel Dti after air cooling from $1200^{\circ} \mathrm{C}$ or more are brittle. The fracture surfaces of steel Dzr are all brittle and do not depend on reheating temperature. Therefore, it is anticipated that the reason why there is a difference between Eqs. (4) and (5) is that the fracture mode is different between the group of steels D, Dca, Dmg, and the group of steels Dti, Dzr.

Large dimples and minute dimples can be seen in the ductile fracture surfaces around the notches of steels D, Dca, and Dmg. There are, or there were sulfides in large dimples. The formation energy of large dimples may be relatively small because they are formed by interface flaking between sulfides and matrix, while the formation energy of minute dimples which are formed by the connection of large dimples may be relatively large. ${ }^{24)}$ The size of large dimples of steels Dca and Dmg are smaller, and the area ratio of minute dimples are larger than those of steel D.

Figure 12 shows the results of instrumented Charpy impact test at $20^{\circ} \mathrm{C}$ of transverse specimens after air cooling from 1100 or $1300^{\circ} \mathrm{C} . U_{1}$ and $U_{2}$ in this figure mean the crack initiation energy and the crack propagation energy, respectively. The impact fracture energy $U$ is the sum of $U_{1}$ and $U_{2}$. While the difference of $U_{2}$ among steels $\mathrm{D}$, Dca, and Dmg is very small, $U_{1}$ of steels Dca and Dmg is much higher than that of steel D. Therefore, impact properties of

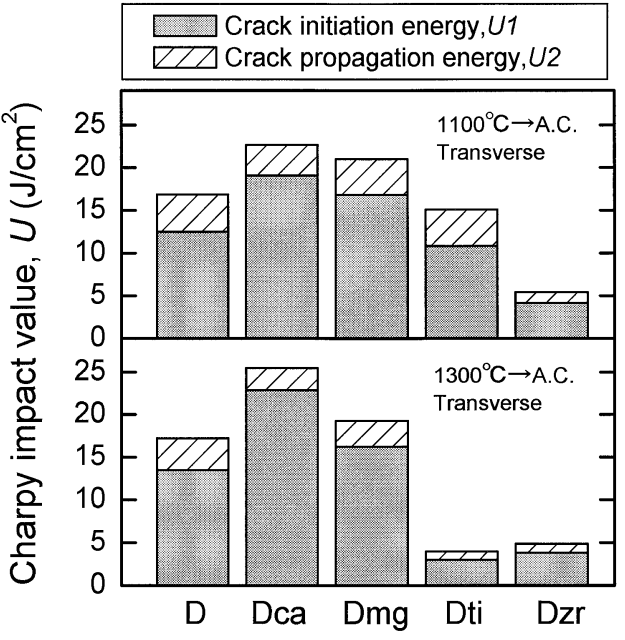

Fig. 12. Crack propagation energy and crack initiation energy of transverse Charpy impact value.

ductile fracture is improved by sulfides shape control because $U_{1}$ improves by the increase of area ratio of minute dimples caused by the decrease of $(K-1) I$.

On the other hand, the reason why the Charpy impact value of steels Dti and Dzr at $20^{\circ} \mathrm{C}$ is low may be related to their brittle fracture. In case of steel Dti, $(\mathrm{Ti}, \mathrm{V}) \mathrm{C}$, which contributes precipitation hardening, makes the matrix brittle because hardness increases with higher reheating tem- 


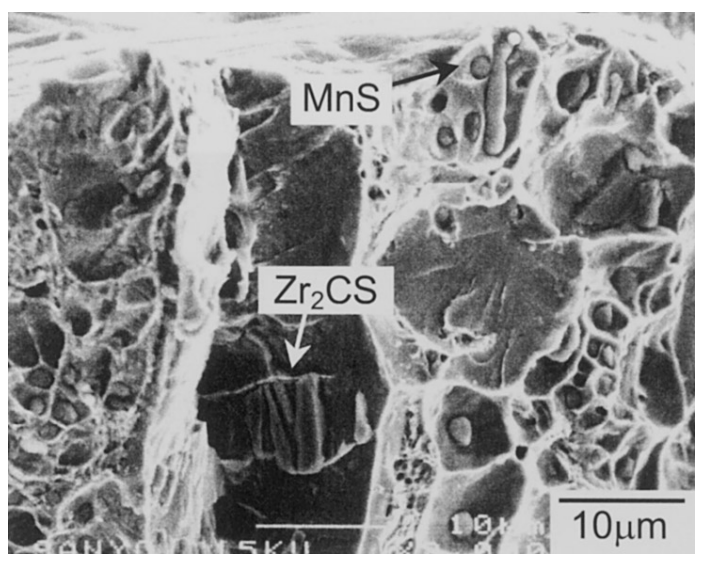

Fig. 13. SEM micrographs of sulfides on the fracture surface of transverse Charpy impact specimen of steel Dzr after cooling from $1300^{\circ} \mathrm{C}$.

perature (see Fig. 4), and the impact properties deteriorate extremely when the reheating temperature is more than $1200^{\circ} \mathrm{C}$ (see Fig. 2). However, the reason why steel Dzr becomes brittle may be different from that for steel Dti because the precipitation hardening inclusions of all specimens except steel Dti are VC. Then the fracture surface of steel Dzr impact specimen were observed in detail by SEMEDX. The results are given in Fig. 13. Dimple patterns are observed around the MnS inclusions while the broken plate-like $\mathrm{Zr}_{2} \mathrm{CS}$ is observed on the cleavage fracture surface. It is believed that when the non-deforming second phase exists in the matrix, the second phase is broken by loading at first, then the stress concentrated to around the end of the crack, and results in promoting the cleavage fracture of the matrix. Fukaura et $a .^{25)}$ reported that large carbides which were broken by loading play a role of triggering fracture, and then the mechanical properties deteriorate. Furthermore, Pickering ${ }^{20)}$ reported that the sulfides morphology affects the voids growth rate, then toughness of plate-like sulfides deteriorates more than that of rod-like sulfides. It is considered that the impact properties of $\mathrm{Zr}_{2} \mathrm{CS}$ in steel Dzr deteriorate by the mechanism above because $\mathrm{Zr}_{2} \mathrm{CS}$ is plate-like and relatively large inclusion. Although $\mathrm{Ti}_{2} \mathrm{CS}$ in steel Dti may work as well as $\mathrm{Zr}_{2} \mathrm{CS}$ in steel Dzr, the deterioration effect of $\mathrm{Zr}_{2} \mathrm{CS}$ on impact properties may be more severe than by $\mathrm{Ti}_{2} \mathrm{CS}$ because rod-like $\mathrm{Ti}_{2} \mathrm{CS}$ is more numerous than plate-like $\mathrm{Ti}_{2} \mathrm{CS}$.

\section{Conclusions}

In this paper, the effects of $\mathrm{S}$ content and $\mathrm{Ca}, \mathrm{Mg}$, $\mathrm{Ti}$, and $\mathrm{Zr}$ addition for sulfides shape control on the impact properties of ferrite-pearlitic microalloyed steels were investigated. The findings are as follows:

(1) The longitudinal Charpy impact value of ferritepearlitic microalloyed steel was improved by addition of $0.05-0.1$ mass $\%$ S. However, transverse Charpy impact value of steel which contained 0.1 mass $\% \mathrm{~S}$ was deteriorated.

(2) Transverse Charpy impact value of steels which contain 0.1 mass $\% \mathrm{~S}$ was improved by the addition of $\mathrm{Ca}$ or
$\mathrm{Mg}$ without changing longitudinal Charpy impact value. However, $\mathrm{Ti}$ or $\mathrm{Zr}$ addition caused both longitudinal and transverse Charpy impact values to deteriorate seriously.

(3) $\mathrm{Ca}$ or $\mathrm{Mg}$ addition to steels produce the sulfides, $(\mathrm{Mn}, \mathrm{Ca}) \mathrm{S}$ or $(\mathrm{Mn}, \mathrm{Mg}) \mathrm{S}$, respectively. These sulfides are more difficult to elongate by hot forging than $\mathrm{MnS}$ inclusions, and control their shape. Therefore, the area ratio of minute dimple patterns in the ductile fracture surface increases. As a result, the crack initiation energy increases, and the transverse Charpy impact value is improved.

(4) $(\mathrm{Ti}, \mathrm{V}) \mathrm{C}$ and rod-like or plate-like $\mathrm{Ti}_{2} \mathrm{CS}$ were generated when $\mathrm{Ti}$ was added to the steel. Large plate-like $\mathrm{Zr}_{2} \mathrm{CS}$ was generated when $\mathrm{Zr}$ was added to the steel. It is believed that the cracks, which initiated in these plate-like sulfides by the loading at the impact test, promoted cleavage fracture because stress concentrated to the end of these cracks. Furthermore, $(\mathrm{Ti}, \mathrm{V}) \mathrm{C}$ made the matrix brittle because (Ti, V)C contributed to precipitation hardening. The deterioration effect of impact properties by $\mathrm{Ti}$ or $\mathrm{Zr}$ addition is caused by these mechanisms.

\section{REFERENCES}

1) N. Tsunekage, K. Kobayashi and H. Tsubakino: CAMP-ISIJ, 13 (2000), 534

2) I. Nomura: Materia Jpn., 34 (1995), 705.

3) T. Ochi, T. Takahashi and H. Takada: Iron Steelmaker, 16 (1988), 21.

4) C. Maeda, S. Yasuda and H. Ishikawa: J. Soc. Auto. Eng. Japan, 43 (1989), 79.

5) Y. Tomita, N. Saito, T. Tsuzuki, Y. Tokunaga and K. Okamoto: ISIJ Int., 34 (1994), 829.

6) S. Suzuki, K. Kuroki, H. Kobayashi and N. Takahashi: Mater. Trans., JIM, 33 (1992), 1068.

7) H. Takada, T. Ochi, F. Ishikawa, S. Yasuda and C. Maeda: Bull. Jpn. Inst. Met., 32 (1993), 429.

8) S. Mizoguchi and J. Takamura: CAMP-ISIJ, 3 (1997), 277.

9) L. Jiang and K. Cui: Steel Res., 68 (1982), 163.

10) K. Tashiro, S. Izumi, T. Mori, T. Harada and Y. Nishi: Tetsu-toHagané, 66 (1980), S533.

11) S. A. El-Ghazaly: Neue Huette, 37 (1992), 399.

12) J. C. Billington and N. J. Keegan: Clean Steel 3, Int. Conf. on Clean Steel (3rd) Balatonfuered, (1987), 39.

13) J. J. Bosley and J. J. Oravec: Proc. Electr. Furn. Conf., 36 (1979), 28.

14) T. Kanou, K. Tsugui and S. Nakamura: Electr. Furn. Steel, 71 (2000), 89

15) Y. Umeda, T. Ikeda, H. Ichihashi, T. Kawai and S. Sugisawa: Sumitomo Met., 33 (1981), 230.

16) M. Fukuda, T. Sawamura, T. Hashimoto and S. Hamanaka: Tetsu-toHagané, 61 (1975), S786.

17) W. M. Garrison, Jr., A. L. Wojcieszynski and L. E. Iorio: Recent Advances in Fracture, TMS, Orlando, (1997), 361.

18) D. Li, Z. Wang, L. Chang, X. Wang and Z. Fan: Arch. Eisenhüettenwes., 54 (1983), 507.

19) H. Kaneko, T. Nishizawa and K Tamaki: J. Jpn. Inst. Met., 27 (1963), 299.

20) F. B. Pickering: Toward Improved Ductility and Toughness, Climax Molybdenum Development Company, ISIJ, Tokyo, (1971), 9.

21) T. Chiba, M. Miyamoto, S. Ikeshita, K. Hamada and T. Satoh: $S A E$ Technical Paper Series, (1996), No. 960310.

22) C. E. Sims and F. B. Dahle: Trans. A.F.A., 46 (1938), 65.

23) H. Morrogh: J. Iron Steel Inst., 154 (1946), 399.

24) H. Kitagawa and R. Koterazawa: Fractography, Baifukan, Tokyo, (1978), 52

25) K. Fukaura, H. Sunada, Y. Yokoyama, K. Teramoto, D. Yokoi and N. Tsujii: Tetsu-to-Hagané, 84 (1998), 230. 